Goldschmidt 2021 Abstract

https://doi.org/10.7185/gold2021.5699

\section{Evidence of interaction of the subducting slab with iron-saturated transition zone of the mantle}

\author{
VLADISLAV S. SHATSKY ${ }^{1,2,3}$, RICHARD WIRTH ${ }^{4}$, \\ ALEXEY L. RAGOZIN ${ }^{1,3}$, ALLA M. LOGVINOVA ${ }^{1}$ AND \\ VIKTORIYA V. KALININA ${ }^{1}$
}

${ }^{1}$ Sobolev Institute of Geology and Mineralogy

${ }^{2}$ Vinogradov Institute of Geochemistry

${ }^{3}$ Novosibirsk State University

${ }^{4}$ GeoForschungsZentrum

Presenting Author: shatsky@igm.nsc.ru

We demonstrate the presence of diamonds from the transition zone in placers deposits in the northeastern area of Siberian craton. Diamond ISTD-72 contains inclusions in which the replacement of chromite by iron oxides is observed. One inclusions contain only iron oxides and fragments of diamonds. The diamond XLS- 82 contains a large inclusion $(200 \mathrm{~mm})$ with a heterogeneous composition (Fig. 1). The compositional maps show areas consisting of magnetite and areas where together with magnetite there are phases containing $\mathrm{Ca}, \mathrm{F}, \mathrm{Mn}$, S. In addition, the inclusion contain monazite crystals ranging in size from 5 to $8 \mu \mathrm{m}$. The FIB/TEM technique used to study inclusions. Areas of inclusions in diamond ISTD-72 composed of iron oxides are nanocrystalline aggregates consisting of magnetite and nanoscale diamonds. Magnetite nanocrystals are usually idiomorphic and have a size $10-100 \mathrm{~nm}$. The composite inclusion in diamond XLS-82 is a mixture of nanocrystalline magnetite, $\mathrm{CaF}_{2}$ and anhydrite. $\mathrm{CaF}_{2}$ usually has a cubic structure, but in some cases, an orthorhombic polymorph has been identified. The structural phase transition of cubic $\mathrm{CaF}_{2}$ to the orthorhombic modification was established at pressures of 8-10 GPa [1]. Taking into account the fact that magnetite is present in the studied inclusions in the form of a nano-crystalline aggregate, it can be concluded that diamonds captured the oxidized iron melt. We believe that the nanocrystalline magnetite aggregate indicates the decomposition of the high-pressure modification of iron oxide $\left(\mathrm{Fe}_{5} \mathrm{O}_{6}\right)$ to $\mathrm{Fe}_{3} \mathrm{O}_{4}$ $+\mathrm{FeO}$ [2]. It is important to note that $\mathrm{Fe}_{5} \mathrm{O}_{6}$ is stable within the forsterite+diamond stability field [3]. Taking into account the available experimental data, it can be concluded that diamonds with inclusions of oxidized iron crystallized in the pressure range of 9-15 GPa. Nanocrystalline inclusions in diamonds indicate the interaction of the subducting slab with iron-saturated transition zone of the mantle.

[1] Cui et al. (2009) Comput. Mater. Sci. 47, 41-45.

[2] Hikosaka et al. (2019) Am. Min. 104, 1356-1359.

[3] Myhill et al. (2016) Contrib. Mineral. Petrol. 171, 51

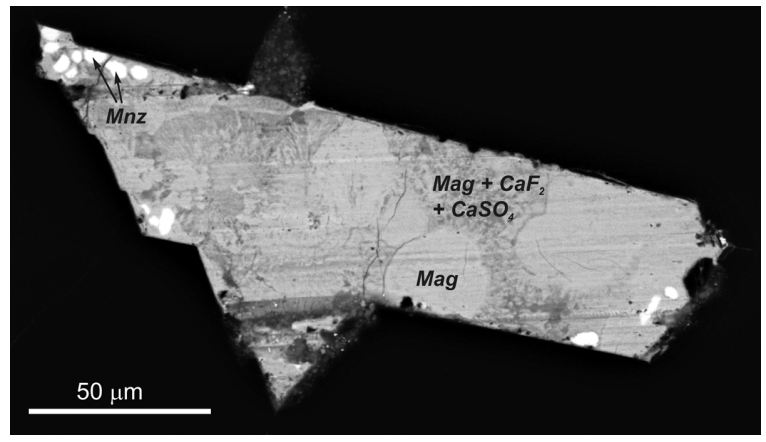

